\title{
Effects of high glucose on proliferation and function of circulating fibrocytes: Involvement of CXCR4/SDF-1 axis
}

\author{
YINGZHENG WENG ${ }^{1,2^{*}}$, JIANGJIE LOU ${ }^{1 *}$, XIAOWEI LIU ${ }^{1}$, SENNA LIN $^{1,3}$, \\ CHENKAI XU ${ }^{1}$, CHANGQING DU ${ }^{1-3}$ and LIJIANG TANG ${ }^{1-3}$ \\ ${ }^{1}$ Department of Cardiology, Zhejiang Hospital, Hangzhou, Zhejiang 310013; ${ }^{2}$ Department of Medicine, \\ School of Medicine, Wenzhou Medical University, Wenzhou, Zhejiang 325035; ${ }^{3}$ Department of Medicine, \\ The Second College of Clinical Medicine, Zhejiang Chinese Medical University, Hangzhou, Zhejiang 310053, P.R. China
}

Received December 3, 2018; Accepted June 6, 2019

DOI: $10.3892 /$ ijmm.2019.4260

\begin{abstract}
The present study aimed to further investigate the effects of high glucose on the function of circulating fibrocytes and its underlying mechanisms. The total peripheral blood mononuclear cells were obtained from normal glucose tolerance patients and type 2 diabetic mellitus patients. Circulating fibrocytes were stimulated with different glucose concentrations for different time periods (24, 48 and $72 \mathrm{~h}$ ). Cell proliferation was determined by Cell Counting Kit- 8 assay. The expression of connective tissue growth factor (CTGF) was detected by western blotting. The expression of COL-I was detected by flow cytometry. The apoptotic bodies of cells were detected by fluorescence microscopy after Hoechst 33258 staining. The invasive and migration abilities of fibrocytes were detected by Transwell chamber assay. Secretion of stromal cell-derived factor 1 (SDF-1) was measured by ELISA. The circulating fibrocytes showed a typical spindle-shape and were double-positive for cluster of differentiation 45 (green) and COL-I (red). Compared with the $5.5 \mathrm{mmol} / 1$ glucose group, a high glucose concentration significantly promoted the proliferation of circulating fibrocytes and showed the most significant effects at $30 \mathrm{mmol} / \mathrm{l}$ after treatment for $48 \mathrm{~h}$. AMD3100 showed no effects on the proliferation of circulating fibrocytes. Flow cytometry revealed that $30 \mathrm{mmol} / \mathrm{l}$ glucose significantly promoted the expression of COL-I vs. $5.5 \mathrm{mmol} / 1$ glucose group $(\mathrm{P}<0.01)$, while AMD3100 reversed this $(\mathrm{P}<0.05)$. Hoechst33258 staining showed no differences in the apoptotic bodies between experimental groups $(\mathrm{P}>0.05)$.
\end{abstract}

Correspondence to: Dr Changqing Du or Dr Lijiang Tang, Department of Cardiology, Zhejiang Hospital, 7 Lingyin Road, Hangzhou, Zhejiang 310013, P.R. China

E-mail: ddcq82@126.com

E-mail: zjyytang@163.com

${ }^{*}$ Contributed equally

Key words: circulating fibrocytes, diabetes, fibrosis, proliferation, invasion and migration, CXC chemokine receptor 4/SDF-1
Western blotting revealed that the expression of CTGF was decreased significantly by AMD3100 pretreatment $(\mathrm{P}<0.01)$. Transwell chamber assay showed that $30 \mathrm{mmol} / 1$ glucose significantly promoted the invasive and transfer abilities $(\mathrm{P}<0.01)$ of fibrocytes when compared with the $5.5 \mathrm{mmol} / \mathrm{l}$ glucose group. While AMD3100 reversed the cell migratory effects induced by high glucose $(\mathrm{P}<0.01)$. In addition, the secretion of SDF-1 stimulated by $30 \mathrm{mmol} / 1$ glucose DMEM showed no differences compared with $5.5 \mathrm{mmol} / 1$ glucose DMEM $(\mathrm{P}>0.05)$. High glucose stimulated the expressions of CTGF and COL-I, and promoted migration of circulating fibrocytes via the $\mathrm{CXC}$ chemokine receptor 4/SDF-1 axis.

\section{Introduction}

Diabetes is one of the major risk factors of cardiovascular disease. Diabetic cardiomyopathy (DCM) is a distinct clinical entity of cardiovascular disease that cannot be explained by coronary atherosclerotic heart disease, hypertensive heart disease and heart disease caused by other factors (1). The disease is associated with metabolic disorders and microvascular lesions, causing a wide range of necrosis and subclinical cardiac dysfunction. This ultimately promotes the occurrence of heart failure, arrhythmia and cardiogenic shock, and even leads to sudden death in some severe cases.

One of the most important characteristics of DCM is myocardial fibrosis (2). According to the traditional concept, the myocardial fibrosis is caused by resident cardiac interstitial fibroblasts, simultaneously involving the proinflammatory process and synthesis of extracellular matrix (ECM) (3). In 1994, Bucala et al (4) found the novel leukocyte subpopulation that expressed COL-I, CD34 and vimentin. As these are obtained from the peripheral blood, they are given the name of circulating fibrocytes.

Circulating fibrocytes are a type of novel and unique cells that are derived from hematopoietic stem cells (HSCs). They are also referred to as 'peripheral blood fibrocytes', 'bone marrow-derived fibrocytes' and 'circulating fibroblast precursors' (5-7). These aliases reflect some common features with the circulating fibrocytes, such as their existence in the peripheral blood, compromise of a minor component $(<1 \%)$ of peripheral blood mononuclear cells (PBMCs) and are 
considered as bone marrow-derived precursor cells of fibroblasts, and myofibroblasts. Circulating fibrocytes synthesize a variety of ECM proteins including type I and III collagens, fibronectin, vimentin and growth factors, playing an important role in the process of multiple pathophysiological states. Chun $\mathrm{Li}$ et al (8) found that the circulating fibrocytes were recruited from the peripheral blood to the lung through the CXC chemokine receptor 4 (CXCR4)/stromal-derived factor-1 (SDF-1) axis and played an important role in bronchopulmonary dysplasia, which eventually led to pulmonary fibrosis. A recent study showed that the blood concentration of fibrocytes expressing CXCR4 was significantly correlated with Hermansky Pudlak syndrome (HPS), which is a genetic disease caused by interstitial lung disease (ILD). The concentration of CXCR4 $4^{+}$in circulating fibrocytes may be used as a new biomarker for the outcome of ILD in patients with HPS (9). Lin et al (10) found that activation of the CXCR4/SDF-1 axis caused expression of CTGF and promoted cell differentiation, eventually leading to interstitial lung fibrosis. These results suggested that fibrocytes might play a crucial role in organ fibrosis through the CXCR4/SDF-1 axis.

Diabetic patients could develop severe organ fibrosis and so a previous study hypothesized that there may be more circulating fibrocytes in the peripheral blood of diabetic patients (11). As expected, our previous study (12) confirmed that the ratio of cells co-expressing cluster of differentiation (CD)45 and COL-I to PBMCs was significantly increased in diabetic patients compared with normal glucose tolerance (NGTs; $1.93 \pm 1.01$ vs. $0.52 \pm 0.35 \% ; \mathrm{P}<0.01$ ) patients. In addition, high glucose promoted the proliferation and the expression of CXCR4 and CTGF of circulating fibrocytes. However, whether high glucose levels regulated the circulating fibrocytes through the CXCR4/SDF-1 axis has not been investigated yet. Therefore, in this study, the effects of high glucose on the function of circulating fibrocytes and its underlying mechanism were explored by investigating i) the effects of high glucose concentration medium on the invasion and migration ability of circulating fibrocytes; ii) the involvement of the CXCR4/SDF-1 axis in the production of ECM COL-I and the fibrogenic factor connective tissue growth factor (CTGF) of circulating fibrocytes, and iii) whether AMD3100, the specific blocker of CXCR4, could relieve the progression of fibrosis. Combined with the authors previous study, it is hoped that the present study will provide a more detailed explanation regarding the effects of high glucose on circulating fibrocytes.

\section{Materials and methods}

Patients. A total of 15 NGT patients (11 males and 4 females) and 15 type 2 diabetes mellitus ( $\left.\mathrm{T}_{2} \mathrm{DM}\right)$ patients $(13$ males and 2 females) from the department of Cardiology, Zhejiang Hospital (Hangzhou, China) were recruited from June 2016 to June 2017. The patients' age ranged from 65-75 years old. Inclusion criteria of NGT patients were as follows: The blood glucose levels should be $<7.8 \mathrm{mmol} / \mathrm{l}$ after $2 \mathrm{~h}$ of oral glucose tolerance test experiment and the $\mathrm{T}_{2} \mathrm{DM}$ patients were confirmed to have type 2 diabetes according to the 1999 WHO diagnostic criteria for diabetes. The exclusion criteria of the patients were as follows: Patients i) with severe heart and kidney dysfunction, such as myocardial infarction (MI), hypertrophic cardiomyopathy; ii) with severe pulmonary infection, chronic obstructive pulmonary disease and interstitial disease; iii) with severe trauma and burns; iv) with stage 2 and 3 hypertension; v) with malignant tumors; vi) taking hormonal drugs recently; vii) with coagulopathy; and viii) with connective tissue diseases. According to the previous literature reports (13-15), these diseases might be associated with an increase in the number of circulating fibrocytes. The present study was approved by the Zhejiang Hospital Ethics Committee and all subjects signed the informed consent form.

Isolation and cultivation of circulating fibrocytes. A total of $25 \mathrm{ml}$ of peripheral blood from NGT patients and $5 \mathrm{ml}$ from $\mathrm{T}_{2} \mathrm{DM}$ patients were obtained and mixed with $1.6 \%$ heparinized normal saline solution. Density gradient centrifugation was performed to obtain the PBMC layer (16). The cell sediment was washed twice with $5 \mathrm{ml}$ PBS at $500 \mathrm{x}$ g for $10 \mathrm{~min}$ at $20^{\circ} \mathrm{C}$ (Genom Biotechnology). The cells were resuspended in $25 \mathrm{mmol} / 1$ glucose DMEM containing (Thermo Fisher Scientific, Inc.) 20\% fetal bovine serum (FBS; Thermo Fisher Scientific, Inc.), penicillin (100 U/ml; Genom Biotechnology) and streptomycin $(100 \mu \mathrm{g} / \mathrm{ml}$; Genom Biotechnology). After that, the cells at a density of $1 \times 10^{6} / \mathrm{ml}$ were seeded into 6 -well plates and placed in a humidified incubator at $37^{\circ} \mathrm{C}$ in $5 \% \mathrm{CO}_{2}$. The medium was changed every 3 days and the non-adherent cells were removed, and the adherent cells were obtained after cultivation for 14 days. The morphological characteristics of the cells were observed under an inverted phase contrast microscope.

Identification of circulating fibrocytes by immunofluorescence. COL-I and CD45 are considered as biomarkers to identify the circulating fibrocytes as mentioned before. The adherent cells were digested with Accutase solution (Yeasen). After washing twice $\left(450 \mathrm{x} \mathrm{g}, 10 \mathrm{~min}, 20^{\circ} \mathrm{C}\right)$, the cells were resuspended with high glucose ( $25 \mathrm{mmol} / \mathrm{l})$ DMEM containing $20 \%$ FBS. After counting, the cells were diluted to $8 \times 10^{4} / \mathrm{ml}$ and placed on coverslips (JingAn Biological) in 24-well plates. After $24 \mathrm{~h}$, the cells were washed twice and fixed with $4 \%$ paraformaldehyde at $20^{\circ} \mathrm{C}$ for $15 \mathrm{~min}$. Then, $200 \mu \mathrm{l}$ fixation and permeabilization solution was added in each well and the coverslips were incubated at $4^{\circ} \mathrm{C}$ for $20 \mathrm{~min}$. The cells were washed with $1 \mathrm{X}$ wash buffer twice and then $100 \mu \mathrm{l}$ FBS was added for $30 \mathrm{~min}$ at $4^{\circ} \mathrm{C}$. The primary antibody, mouse anti-human CD45 (1:100; Ancell; cat. no. 196-030) and rabbit anti-human COL-I (1:500; Rockland Immunochemicals, Inc.; cat. no. 600-401-103S) were added to the cells and then the coverslips were incubated overnight at $4^{\circ} \mathrm{C}$. After washing twice, the cells were incubated with Alexa Fluor 488 labeled goat anti-mouse immunoglobulin (Ig) G (1:200; Yeasen; cat. no. 33206ES60) and Alexa Fluor 594 labeled goat anti-rabbit IgG secondary antibody (1:200; Yeasen; cat. no. 33112ES60) for $30 \mathrm{~min}$ at $4^{\circ} \mathrm{C}$. After washing twice, DAPI (Abcam) was added and incubated for $5 \mathrm{~min}$ at $4^{\circ} \mathrm{C}$, washed with PBST $(0.1 \%$ tween 20$)$ twice and then observed under a confocal microscope.

Measurement of proliferation of circulating fibrocytes by Cell Counting Kit (CCK)-8. After 14 days of culture, the circulating fibrocytes obtained from the NGT group were digested 
by Accutase solution, diluted to $4 \times 10^{4} / \mathrm{ml}$ and seeded in 96-well plates. After $24 \mathrm{~h}$ incubation, the cells were synchronized with minimum Eagle's medium (MEM; $5.5 \mathrm{mmol} / 1$ glucose; Gibco; Thermo Fisher Scientific, Inc.) for $24 \mathrm{~h}$. After that, $100 \mu \mathrm{l}$ of $5.5 \mathrm{mmol} / \mathrm{l}$ glucose DMEM, $5.5 \mathrm{mmol} / \mathrm{l}$ glucose $+100 \mu \mathrm{mol} / 1$ AMD3100 DMEM (MedChem Express) $30 \mathrm{mmol} / 1$ glucose DMEM and $30 \mathrm{mmol} / 1$ glucose $+100 \mu \mathrm{mol} / 1$ AMD3100 DMEM, respectively were added. After 24, 48 and $72 \mathrm{~h}$ incubation, the intervention solution was aspirated and stored at $-80^{\circ} \mathrm{C}$ for subsequent experiments. A total of $100 \mu \mathrm{l}$ MEM containing $10 \%$ CCK-8 (7sea biotech) was added to each well and continued to culture for $1 \mathrm{~h}$ for measuring the absorbance at $450 \mathrm{~nm}$ using a microplate reader (Thermo Fisher Scientific, Inc.).

Measurement of cell apoptosis by Hoechst33258 staining. The circulating fibrocytes from NGT patients were diluted to $5 \times 10^{4} / \mathrm{ml}$ and then seeded in 24-well plates. After $24 \mathrm{~h}$ incubation, the fibrocytes were synchronized with MEM for $24 \mathrm{~h}$. Then cells were treated with $5.5 \mathrm{mmol} / \mathrm{l} \mathrm{DMEM}, 30 \mathrm{mmol} / \mathrm{l}$ DMEM and $5.5 \mathrm{mmol} / \mathrm{l} \mathrm{DMEM}+200 \mu \mathrm{mol} / 1 \mathrm{H}_{2} \mathrm{O}_{2}$ (as positive control group) for $48 \mathrm{~h}$. After treatment with different concentrations of DMEM, cells were fixed with $4 \%$ paraformaldehyde at $20^{\circ} \mathrm{C}$ for $15 \mathrm{~min}$. After that, $0.5 \mu \mathrm{g} / \mathrm{ml}$ Hoechst33258 (R\&D Systems, Inc.) was added for $15 \mathrm{~min}$ in the dark. Synchronized cells without any DMEM interventions were stained at $20^{\circ} \mathrm{C}$ for $15 \mathrm{~min}$ with $0.5 \mu \mathrm{g} / \mathrm{ml}$ Hoechst 33258 and served as a negative control. Finally, the morphology and brightness of the nucleus of circulating fibrocytes were observed under confocal microscopy (Leica Microsystems $\mathrm{GmbH}$ ). The excitation wavelength was $550 \mathrm{~nm}$.

Detection of COL-I expression of fibrocytes by flow cytometry. After 7 days of cultivation, the fibrocytes of NGT patients were diluted to $6 \times 10^{4} / \mathrm{ml}$ and synchronized with MEM for $24 \mathrm{~h}$. After synchronization, $1 \mathrm{ml}$ of $5.5 \mathrm{mmol} / 1 \mathrm{DMEM}, 5.5 \mathrm{mmol} / 1 \mathrm{DMEM}+100 \mu \mathrm{mol}$ AMD3100, $30 \mathrm{mmol} / 1 \mathrm{DMEM}$ and $30 \mathrm{mmol} / 1$ of DMEM+ $100 \mu \mathrm{mol}$ AMD3100 were added, respectively. After $48 \mathrm{~h}$, the fibrocytes were digested by Accutase solution. All the cells were collected after centrifugation $(450 \mathrm{x}$ g for $10 \mathrm{~min}$ at $20^{\circ} \mathrm{C}$ ) and then were treated with cytofix/cytoperm solution (Abcam) for $20 \mathrm{~min}$, followed by the addition of $100 \mu \mathrm{l} \mathrm{FBS}$ for $30 \mathrm{~min}$ at $4^{\circ} \mathrm{C}$. The primary antibody, rabbit anti-human COL-I (1:2,000; Abcam; cat. no. ab6577) was applied to the cells and incubated at $4^{\circ} \mathrm{C}$ overnight. Then the goat anti-rabbit fluorescein isothiocyanate-IgG $(1: 1,000$; Abcam; cat. no. ab6717) was added for 20 min in the dark. After staining, the expression of COL-I was detected by Cytomics $^{\mathrm{TM}}$ FC 500 and the non-stained cells were used as isotype controls. The results were analyzed using Flowjo software (Tree Star, Inc.; version 7.6.1).

Invasion and chemotaxis assay of fibrocytes. After 14 days of cultivation, the fibrocytes of NGTs were diluted to $8 \times 10^{4} / \mathrm{ml}$ and synchronized with MEM for $24 \mathrm{~h}$. After that, the fibrocytes were treated with 5.5 and $30 \mathrm{mmol} / 1$ of DMEM, respectively for $48 \mathrm{~h}$. A Transwell chamber with an $8 \mu \mathrm{m}$ pore PET membrane (Corning Inc.) was used for evaluating the invasion and chemotaxis of fibrocytes. Matrigel was diluted with serum-free MEM (1:8), coated on the upper chamber of the bottom membrane of the Transwell chamber and then placed at $37^{\circ} \mathrm{C}$ for $30 \mathrm{~min}$ for solidification. Stimulated fibrocytes were digested by Accutase solution, diluted with serum-free MEM to $5 \times 10^{4} / \mathrm{ml}$ and seeded onto the upper chambers $(150 \mu \mathrm{l}$ per well). The lower chambers were filled with different concentrations of $25 \mathrm{mmol} / 1$ glucose DMEM containing 20\% FBS [25 mmol/1 glucose DMEM, $25 \mathrm{mmol} / 1$ glucose DMEM+50 $\mu \mathrm{mol} / 1 \mathrm{SDF}-1$ (R\&D Systems, Inc.), $25 \mathrm{mmol} / 1$ glucose DMEM+100 $\mu \mathrm{mol} / 1 \mathrm{AMD} 3100$ and $25 \mathrm{mmol} / 1$ glucose $\mathrm{DMEM}+50 \mu \mathrm{mol} / 1$ and SDF-1+100 $\mu \mathrm{mol} / 1 \mathrm{AMD} 3100]$. The whole culture system was placed into a humidified incubator with $5 \% \mathrm{CO}_{2}$. After $48 \mathrm{~h}$, the matrigel was removed. The cells were fixed with $4 \%$ paraformaldehyde for $15 \mathrm{~min}$ at $20^{\circ} \mathrm{C}$ and then stained with $1 \%$ crystal violet solution for $10 \mathrm{~min}$ at $20^{\circ} \mathrm{C}$ (Yantuo Shanghai Trade, Co., Ltd.). Finally, the cells were observed under inverted phase contrast microscope and the total cell number of five non-overlapping fields was counted.

Measurement of SDF-1 secretion by ELISA. A $5.5 \mathrm{mmol} / \mathrm{l}$ supernatant and $30 \mathrm{mmol} / 1$ glucose DMEM were obtained as described in the above section. The DMEM was centrifuged at $10,000 \times \mathrm{g}$ for $10 \mathrm{~min}$ at $4^{\circ} \mathrm{C}$. The content of SDF-1 in the supernatants was quantified using a commercial SDF-1 ELISA kit (PeproTech, Inc.; cat. no. 900-K92) according to the manufacturer's protocol. The detection limitation was $100 \mathrm{pg} / \mathrm{ml}$.

Measurement of CTGF by western blotting. The identified circulating fibrocytes of NGT patients were diluted to $8 \times 10^{4} / \mathrm{ml}$. The cells were seeded into 6-well plates. After $24 \mathrm{~h}$ of synchronization, each well was added with $5.5 \mathrm{mmol} / 1$ glucose DMEM, $5.5 \mathrm{mmol} / 1$ glucose DMEM+100 $\mu \mathrm{mol} / 1$ AMD3100, $30 \mathrm{mmol} / 1$ glucose DMEM and $30 \mathrm{mmol} / \mathrm{l}+100 \mu \mathrm{mol} / \mathrm{l}$ AMD3100 $1 \mathrm{ml}$, respectively for $48 \mathrm{~h}$. Total protein was extracted after intervention and the protein concentration was determined by the bicinchoninic acid method. A total of $20 \mu \mathrm{g}$ of each sample was taken for electrophoresis and then transferred onto the polyvinylidene difluoride (PVDF) membrane. The PVDF membranes were incubated with 5\% milk in TBST $(0.1 \%$ tween 20$)$ buffer for $1 \mathrm{~h}$ at $20^{\circ} \mathrm{C}$. Specific primary antibody [1:1,000; rabbit anti-human CTGF IgG (Abcam; cat. no. ab227180) and mouse anti-human $\beta$-actin IgG (Abcam; cat. no. ab6276)] were added and then the membranes were incubated with 1:5,000 diluted goat anti-mouse (Abcam; cat. no. ab205719) and goat anti-rabbit (Abcam; cat. no. ab205718) horseradish peroxidase labeled secondary antibodies for $1 \mathrm{~h}$ at $20^{\circ} \mathrm{C}$. Finally, $300 \mu \mathrm{l} \mathrm{ECL}$ operating fluid (Abcam) was added per band. Quantitative data were obtained with the ChemiDoc XRS gel imaging system and gray values were analyzed using Image $\mathbf{J}$ software (National Institutes of Health; version 1.8.0).

Statistical analysis. Data was analyzed by SPSS 19.0 software (IBM Corp.) and the results were expressed as the mean \pm standard deviation. Comparison between groups $(>2)$ was performed using one-way analysis of variance (ANOVA) and the between pair differences were performed using least significant difference test. Prior to one-way ANOVA, the normality was confirmed using the Shapiro-Wilk test $(\mathrm{P}>0.05)$ 
Table I. Basic information of T2DM and NGTs.

\begin{tabular}{lcccccc}
\hline Group & $\mathrm{n}$ & Age (year) & Male/female & BMI & HbA1c & Fasting blood glucose \\
\hline NGTs & 15 & $70.33 \pm 5.22$ & $11 / 4$ & $23.77 \pm 3.54$ & $5.27 \pm 0.49$ & $5.41 \pm 0.66$ \\
T2DM & 15 & $72.67 \pm 6.88$ & $13 / 2$ & $26.58 \pm 4.93$ & $7.78 \pm 0.53$ & $7.34 \pm 0.71$ \\
P-value & & $>0.05$ & & $<0.01$ & $<0.01$ & $<0.01$ \\
\hline
\end{tabular}

T2DM, type 2 diabetes; NGT, normal glucose tolerance; BMI, body mass index.
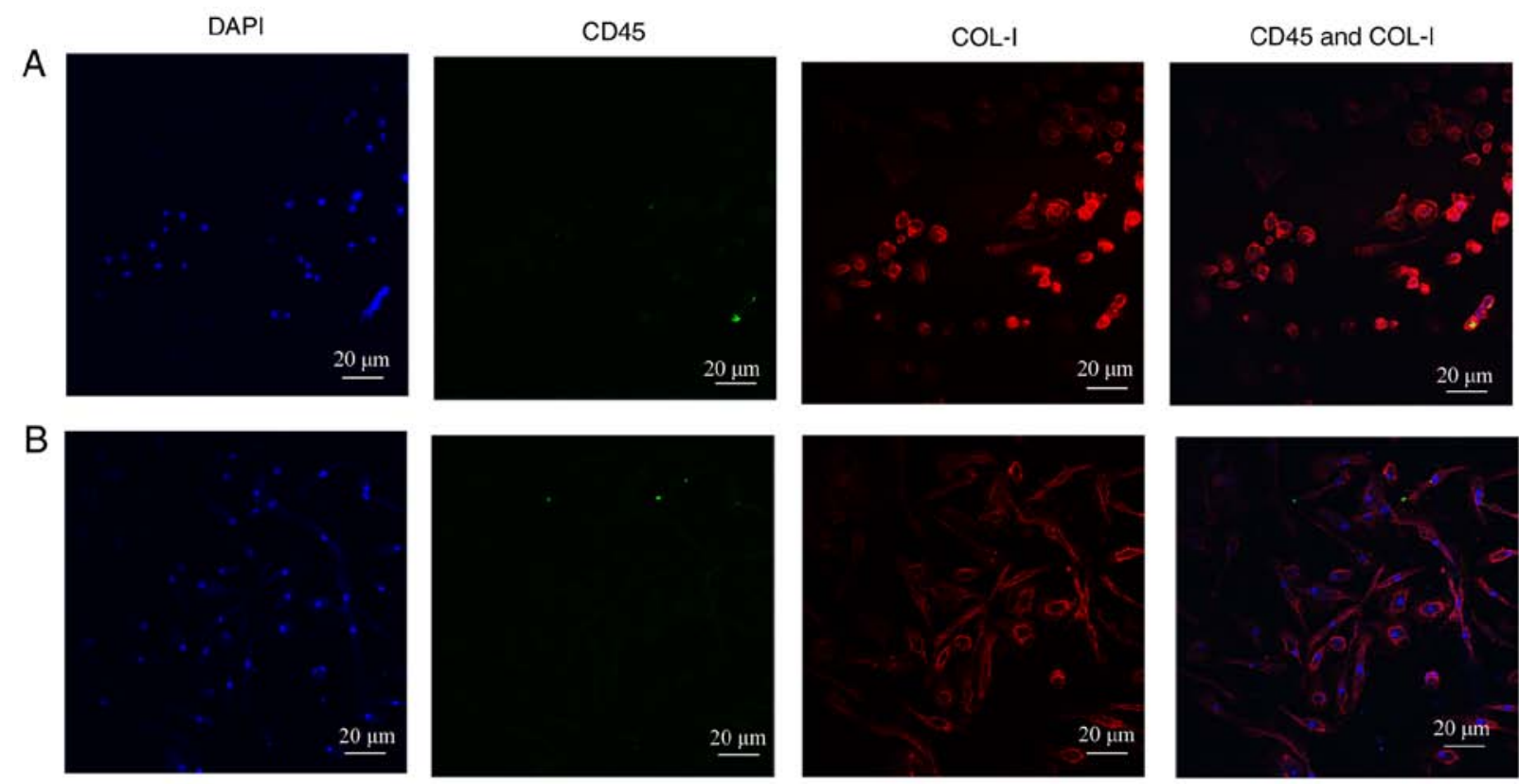

Figure 1. Identification of cultured fibrocytes (magnification, 400). (A) NGTs' PBMCs after 21 days' culture. The cultured cells only expressed COL-I (red) obviously. (B) Diabetic PBMCs after 21 days' culture. The cultured cells only expressed COL-I (red) obviously. Compared with the NGT group, there were more spindle-like cells in diabetic circulating fibrocytes. PMBC, peripheral blood mononuclear cells; NGT, normal glucose tolerance.

and the homogeneity of variances using the $\mathrm{F}$ test $(\mathrm{P}>0.05)$. $\mathrm{P}<0.05$ was considered to indicate a statistically significant difference.

\section{Results}

Basic patient information. The clinical information of all included subjects was collected and the important sections are presented in Table I. The results showed no differences in age between the NGT group and the $\mathrm{T}_{2} \mathrm{DM}$ group $(\mathrm{P}>0.05)$, but showed statistically significant differences between the two groups in the parameters of fasting blood glucose, body mass index and hemoglobin A1c $(\mathrm{P}<0.05)$.

Identification of human circulation fibrocytes. According to the previous studies, $\mathrm{CD} 45^{+} \mathrm{COL}-\mathrm{I}^{+}$or $\mathrm{CD} 34^{+} \mathrm{COL}-\mathrm{I}^{+}$was regarded as the gold standard to identify human circulating fibrocytes $(4,8,9)$. Immunofluorescence technique was used to examine whether the cultured-adherent cells were the target objects. The dyed cells were observed by Olympus FV3000 confocal microscope after immunofluorescence staining. As described in our previous study (12), after 14 days of cultivation, both CD45 (green fluorescence) and COL-I (red fluorescence) showed significant expression in the authors previous research. In addition, there were more spindle-shaped fibrocytes in $\mathrm{T}_{2} \mathrm{DM}$ patients compared with NGT patients. However, after 21 days, the fibrocytes showed only COL-I expression and CD45 expression was hardly observed (Fig. 1A and B). The results were consistent with the differentiation process of circulating fibrocytes as reported in the literatures $(17,18)$. As is known, the expression of hematopoietic surface antigens, like CD34 and CD45, are decreased during the differentiation process of circulating fibrocytes, and at the same time, the secretion of ECM proteins, like COL-I are increased. Finally, the appearance of $\alpha$-smooth muscle actin (sma) indicated that the circulating fibrocytes were completely differentiated into myofibroblasts (5).

AMD3100 had no effect on high glucose induced proliferation of circulating fibrocytes. The proliferation of circulating fibrocytes after treatment with different glucose concentrations of $\operatorname{DMEM}(5.5,25$ and $30 \mathrm{mmol} / \mathrm{l}$ glucose DMEM and $5.5 \mathrm{mmol} / \mathrm{l}$ glucose $+30 \mathrm{mmol} / 1 \mathrm{mannitol})$ stimulation was detected by CCK-8 reagent as done in the our earlier study (12). As is known, the osmotic pressure of the culture media had an effect on the growth and proliferation of the cells $(19,20)$. The osmotic 


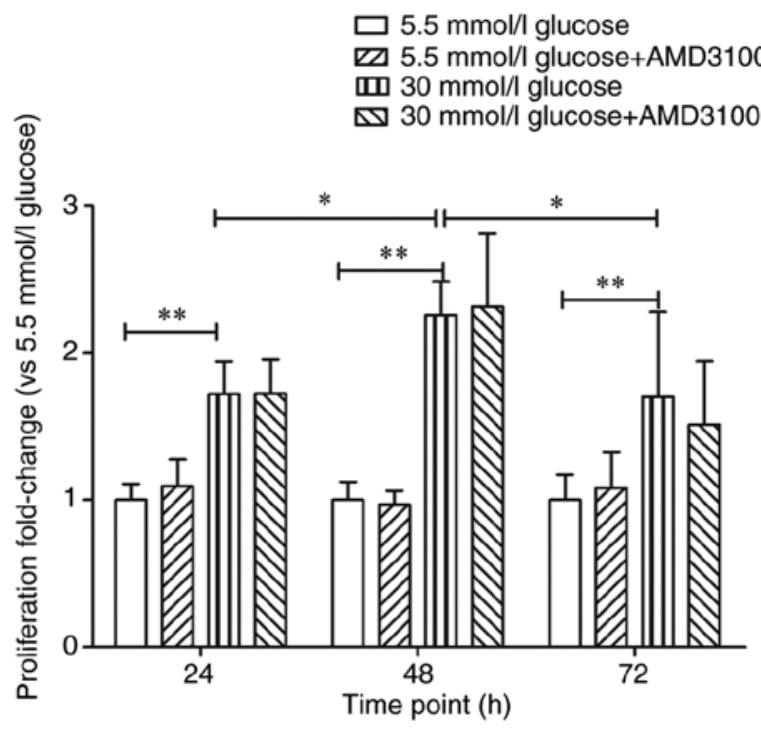

Figure 2. Effect of high glucose DMEM and AMD3100 to the proliferation of circulating fibrocytes. Effect of AMD3100 (the specific inhibitor of CXCR4) on the proliferation of circulating fibrocytes stimulated by high glucose DMEM. Optical density of $5.5 \mathrm{mmol} / 1$ glucose DMEM in each time point $(24,48$ and $72 \mathrm{~h})$ as the control group, $30 \mathrm{mmol} / 1$ glucose vs. $30 \mathrm{mmol} / 1$ glucose+AMD3100 in each time point $(24,48$ and $72 \mathrm{~h}) .{ }^{*} \mathrm{P}<0.05$ and ${ }^{* *} \mathrm{P}<0.01$. DMEM, Dulbecco's modified Eagle's medium.

pressure of $5.5 \mathrm{mmol} / \mathrm{l}$ glucose DMEM was different from that of $30 \mathrm{mmol} / 1$ glucose DMEM. Therefore, in the our previous experiment (12), the $5.5 \mathrm{mmol} / \mathrm{l}$ glucose $+30 \mathrm{mmol} / \mathrm{l}$ mannitol group was added as a negative control group to exclude the influence of osmotic pressure to cell proliferation. In fact, there are a number of similar experiments for measuring cell proliferation that choose mannitol as a negative control $(21,22)$. The results showed that the number of cells was proportional to the value of absorbance. As expected, the proliferation of circulating fibrocytes showed a significant concentration-time correlation. Furthermore, when stimulated with $30 \mathrm{mmol} / \mathrm{l}$ glucose DMEM for $48 \mathrm{~h}$, the number of fibrocytes reached the maximum value. Mannitol intervention did not promote the proliferation of fibrocytes when compared with the $5.5 \mathrm{mmol} / \mathrm{l}$ glucose group (12).

Existing data demonstrated that CXCR4/SDF-1 axis plays a key role in tumor cells proliferation. Marchesi et al (23) found that human pancreatic tumor cells showed higher expression levels of CXCR4 compared with normal and AMD3100 partially inhibited the proliferation of tumor cells. Therefore, it was hypothesized that high glucose stimulated cell proliferation through the CXCR4/SDF-1 axis. Whether AMD3100 could inhibit the proliferation of circulating fibrocytes was then investigated. The absorbance of $5.5 \mathrm{mmol} / \mathrm{l}$ glucose DMEM at $24 \mathrm{~h}$ was regarded as ' 1 ', the proliferation fold-change of $5.5 \mathrm{mmol} / 1$ glucose $+100 \mu \mathrm{mol} / 1$ AMD3100 DMEM group, $30 \mathrm{mmol} / 1$ glucose DMEM group and $30 \mathrm{mmol} / 1$ glucose $+100 \mu \mathrm{mol} / 1$ AMD3100 DMEM group at $24 \mathrm{~h}$ were $1.09 \pm 0.18(\mathrm{P}>0.05), 1.72 \pm 0.22(\mathrm{P}<0.01)$ and $1.72 \pm 0.23(\mathrm{P}<0.01)$ respectively. However, there were no statistical differences between $5.5 \mathrm{mmol} / \mathrm{l}$ glucose DMEM group and $5.5 \mathrm{mmol} / \mathrm{l}$ glucose $+100 \mu \mathrm{mol} / 1$ AMD3100 DMEM group $(\mathrm{P}>0.05)$ or $30 \mathrm{mmol} / 1$ glucose DMEM group and $30 \mathrm{mmol} / 1$ glucose $+100 \mu \mathrm{mol} / 1$ AMD3100 DMEM group

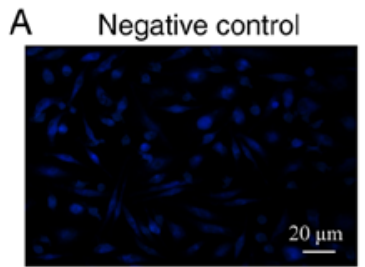

$30 \mathrm{mmol} / \mathrm{l}$ glucose
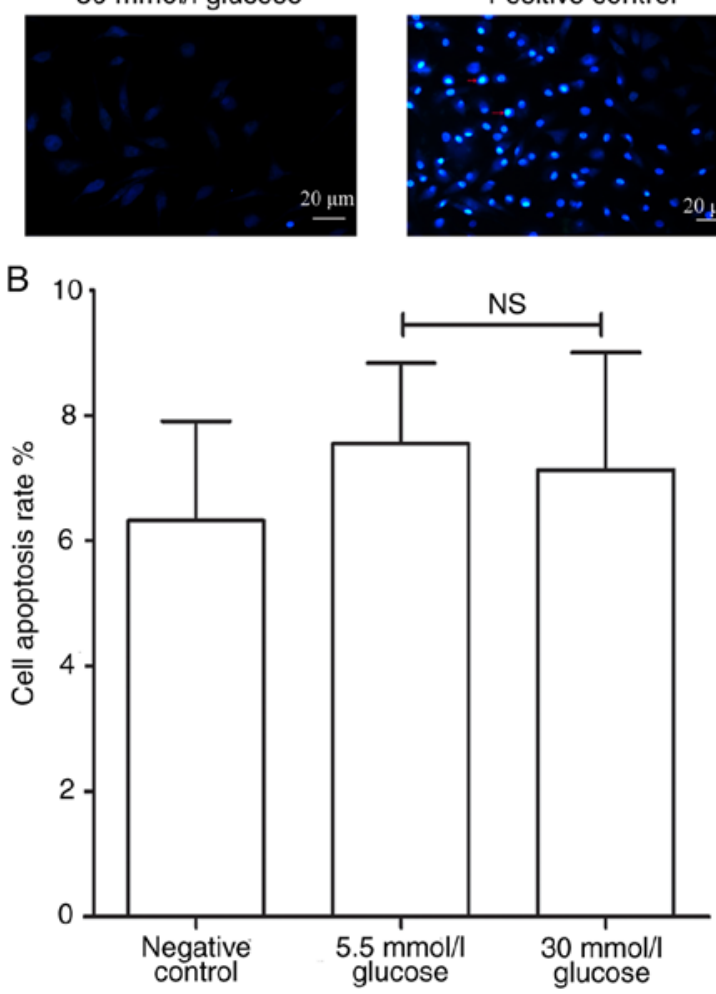

Figure 3. Effect of high glucose DMEM on the apoptosis of circulating fibrocytes (magnification, 400). (A) Representative results of Hoechst33258 staining after treated with different glucose DMEM; the nucleus of early apoptotic cells showing a bright blue (red arrows). (B) Proportion of early apoptotic cells in each group; vs. $5.5 \mathrm{mmol} / 1$. Ns, not significant; DMEM, Dulbecco's modified Eagle's medium.

$(\mathrm{P}>0.05)$. The absorbance of $5.5 \mathrm{mmol} / 1$ glucose DMEM at $48 \mathrm{~h}$ was regarded as ' 1 ' and the proliferation fold-change of sequential intervention groups at $48 \mathrm{~h}$ were $0.97 \pm 0.10$ $(\mathrm{P}>0.05), 2.26 \pm 0.23(\mathrm{P}<0.01)$ and $2.32 \pm 0.50 \quad(\mathrm{P}<0.01)$, respectively. The absorbance of $5.5 \mathrm{mmol} / 1$ glucose DMEM at $72 \mathrm{~h}$ was regarded as ' 1 ' and the proliferation fold-change of sequential intervention groups at $72 \mathrm{~h}$ were $1.08 \pm 0.24$ $(\mathrm{P}>0.05), 1.70 \pm 0.58(\mathrm{P}<0.01)$ and $1.55 \pm 0.43 \quad(\mathrm{P}<0.01)$, respectively. Similarly, AMD3100 showed no effect on the proliferation of circulating fibrocytes at 48 and $72 \mathrm{~h}$. At the same time, although the fold-change was slightly different from the authors' study, the proliferation of cells reached peak at $48 \mathrm{~h}(\mathrm{P}<0.05)$. The results confirmed that high glucose DMEM promoted the proliferation of circulating fibrocytes. However, AMD3100 showed no effects on the proliferation of circulating fibrocytes (Fig. 2).

High glucose had no effect on the apoptosis of circulating fibrocytes. The effects of glucose concentration on apoptosis of circulating fibrocytes was further studied. In order to make the results more convincing, a negative control group and a $\mathrm{H}_{2} \mathrm{O}_{2}$ 

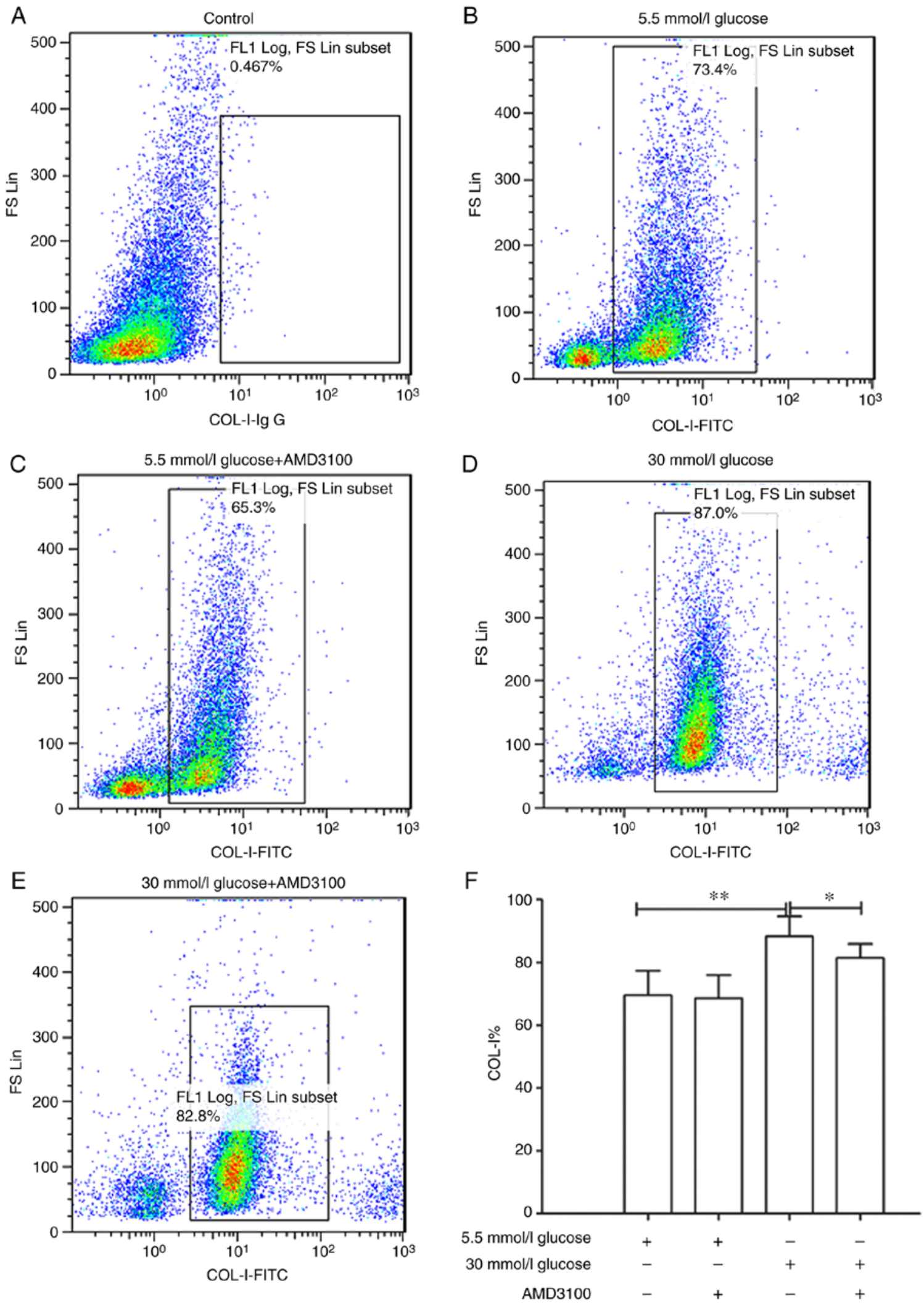

Figure 4. Effect of high glucose Dulbecco's modified Eagle's medium and AMD3100 on the expression of COL-I in circulating fibrocytes. (A) Negative isotype control without staining. (B) $5.5 \mathrm{mmol} / 1$ glucose. (C) $5.5 \mathrm{mmol} / 1$ glucose+AMD3100. (D) $30 \mathrm{mmol} / 1$ glucose. (E) $30 \mathrm{mmol} / 1$ glucose+AMD3100. (F) Statistical chart of COL-I expressing fibrocytes in each group. ${ }^{*} \mathrm{P}<0.05$ and ${ }^{* * *} \mathrm{P}<0.01$. FITC, fluorescein isothiocyanate; Ig, immunoglobulin.

induced positive control group were established. Due to damage of the nuclear envelope occurring at early apoptosis, Hoechst 33258 bound to nucleic acid. The nucleus of the circulating fibrocytes of the positive control group therefore showed a bright blue color after staining (Fig. 3A). The results of Hoechst33258 staining showed no statistically significant difference in the apoptotic rate between $5.5 \mathrm{mmol} / 1$ glucose group and $30 \mathrm{mmol} / \mathrm{l}$ glucose group $(7.33 \pm 1.61$ vs. $7.08 \pm 2.05 \%$; P $>0.05$, Fig. $3 \mathrm{~B})$. 


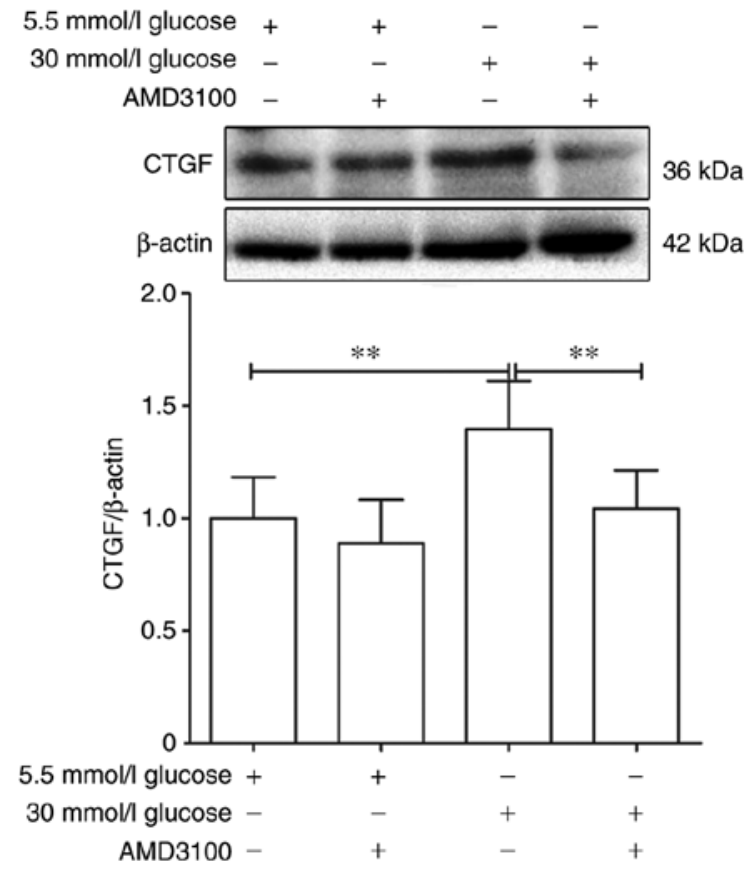

Figure 5. Effects of different glucose concentration DMEM and AMD3100 on the expression of CXCR4 and CTGF of circulating fibrocytes. Effect of AMD3100 on the expression of CTGF in circulating fibrocytes after different glucose DMEM intervention. ${ }^{* *} \mathrm{P}<0.01$ vs. $5.5 \mathrm{mmol} / 1 \mathrm{DMEM}$. DMEM, Dulbecco's modified Eagle's medium; CTGF, connective tissue growth factor.

AMD3100 inhibits high glucose induced promotion of COL-I expression on circulating fibrocytes. Deposition of ECM proteins are one of the most important features of organ fibrosis. Rodríguez-Nieves et al (24) found that the CXCR4/SDF-1 axis mediated myofibroblast phenoconversion and promoted the expression of $\alpha$-sma and COL-I via non-canonical epithelial growth factor receptor/dual specificity mitogen-activated protein kinase kinase 1/extracellular signal-regulated kinase (ERK) signaling. Therefore, whether glucose concentration affected the expression of COL-I was investigated. The results showed that $30 \mathrm{mmol} / 1$ glucose DMEM significantly promoted the expression of COL-I compared with $5.5 \mathrm{mmol} / 1$ group (88.26 \pm 6.40 vs. $69.57 \pm 7.79 \%$; $\mathrm{P}<0.01)$. In addition, AMD3100 could significantly inhibit the promotion of COL-I expression caused by high glucose DMEM (88.26 \pm 6.40 vs. $80.43 \pm 4.42 \%$; $\mathrm{P}<0.05)$. These results demonstrated that high glucose DMEM may stimulate the expression of COL-I via the CXCR4/SDF-1 axis (Fig. 4B-F).

AMD3100 inhibits high glucose induced promotion of CTGF on circulating fibrocytes. CTGF belonged to a new class of cysteine-rich growth factor family and promoted cell proliferation, migration and differentiation $(25,26)$. Recently, several studies have shown a close relationship between CTGF and organ fibrosis: Wang et al (27) found that miR-30c played an important role in the initiation and progression of diabetic nephropathy by targeting CTGF. A further study revealed that Rapamycin upregulated the expression of CTGF in hepatic progenitor cells via TGF- $\beta$-Smad 2 dependent signaling, which serves a critical role in liver fibrosis (28). Guan and Zhou (29) revealed that the knockdown of FZD7 inhibited the TGF- $\beta 1$-induced expression of $\alpha$-SMA, collagen I, fibronectin and CTGF. Our previous study (12) confirmed that the expressions of CXCR4 and CTGF were concentration dependent after treatment with different glucose concentrations of DMEM when compared with the $5.5 \mathrm{mmol} / 1$ glucose DMEM group.

To further explore whether the CXCR4/SDF-1 axis was involved in the fibrotic process caused by high glucose DMEM, AMD3100 was used to block the CXCR4/SDF-1 axis. The expression of CTGF of $5.5 \mathrm{mmol} / 1$ glucose DMEM group was regarded as ' 1 '. After intervention for $48 \mathrm{~h}$, the expression of CTGF was decreased significantly by $30 \mathrm{mmol} / 1$ glucose $+100 \mu \mathrm{mol} / 1$ AMD3100 DMEM compared with $30 \mathrm{mmol} / 1$ glucose DEMM group $(1.75 \pm 0.27$ vs. $1.01 \pm 0.19$; $\mathrm{P}<0.01)$, while showed no significant difference between $5.5 \mathrm{mmol} / \mathrm{l}$ glucose group and $5.5 \mathrm{mmol} / 1$ glucose $+100 \mu \mathrm{mol} / 1$ AMD3100 DMEM group $(1 \pm 0.21$ vs. $0.86 \pm 0.22, \mathrm{P}>0.05$; Fig. 5). These results demonstrated that AMD3100 could significantly inhibit the expression of CTGF.

High glucose promotes transfer and invasive ability of circulating fibrocytes. To explore the effects of high glucose on the invasive and transfer abilities of circulating fibrocytes, a cell chemotaxis assay was performed. As some cells pass through the membrane and are adsorbed on the lower chamber, the total number of cells was defined as the number of cells on the basement membrane plus the number of cells in the lower chamber (Fig. 6A and B). As expected, $30 \mathrm{mmol} / 1$ glucose DMEM significantly promoted the invasive ability of cells $[72.8 \pm 16.42$ vs. $13.2 \pm 5.35(\mathrm{P}<0.01)$ ], compared with $5.5 \mathrm{mmol} / 1$ glucose DMEM group. Also, $30 \mathrm{mmol} / 1$ glucose DMEM+SDF-1 group significantly increased the number of transmembrane fibrocytes $[254.8 \pm 34.2$ vs. $72.4 \pm 16.42(\mathrm{P}<0.01)]$ compared with $30 \mathrm{mmol} / 1$ glucose DMEM group. This promotion could also be blocked by AMD3100 (134.6 \pm 17.78 vs. 254.8 \pm 34.52 ; Fig. 6C). Similar results were obtained in $5.5 \mathrm{mmol} / 1$ glucose groups (data not shown). On the other hand, the number of cells affected by chemokines to migrate through membrane was defined as the total number of 5.5/30 mmol/1 glucose+SDF-1 DMEM group minus 5.5/30 $\mathrm{mmol} / 1$ glucose DMEM group. The results revealed that high glucose significantly promoted the migration of fibrocytes $[181.4 \pm 36.26$ vs. $30.6 \pm 11.64$ $(\mathrm{P}<0.01$; Fig. 6D)].

High glucose DMEM had no effect on the secretion of SDF-1. The effects of glucose concentration on the secretion of SDF-1 of circulating fibrocytes at different time points $(24,48$ and $72 \mathrm{~h})$ were further explored. The results showed no significant differences between $5.5 \mathrm{mmol} / \mathrm{l}$ glucose group and $30 \mathrm{mmol} / \mathrm{l}$ glucose group at any time point $(24 \mathrm{~h}: 186.02 \pm 59.05 \mathrm{pg} / \mathrm{ml}$ vs. $209.36 \pm 71.42 \mathrm{pg} / \mathrm{ml} ; \mathrm{P}>0.05 ; 48$ h: $502.98 \pm 106.1 \mathrm{pg} / \mathrm{ml}$ vs. $503.46 \pm 205.82 \mathrm{pg} / \mathrm{ml} ; \mathrm{P}>0.05 ; 72 \mathrm{~h}: 193.80 \pm 92.30 \mathrm{pg} / \mathrm{ml}$ vs. $186.20 \pm 74.87 \mathrm{pg} / \mathrm{ml} ; \mathrm{P}>0.05)$. However, the secretion of SDF-1 reached peak at $48 \mathrm{~h}$ when compared with 24 and $72 \mathrm{~h}$ $(\mathrm{P}<0.01$; Fig. 7).

\section{Discussion}

The present study demonstrated that high glucose in vitro stimulated the proliferation, invasive and transfer abilities of circulating fibrocytes and promoted the expression of ECM proteins including COL-I and CTGF. Moreover, AMD3100, 
A
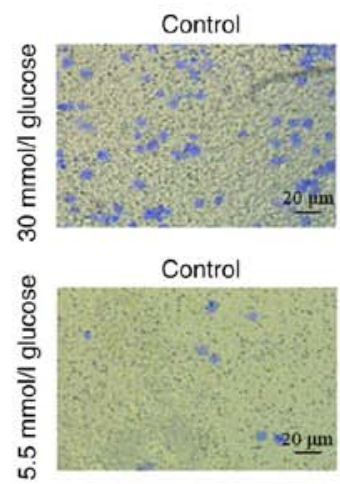

B
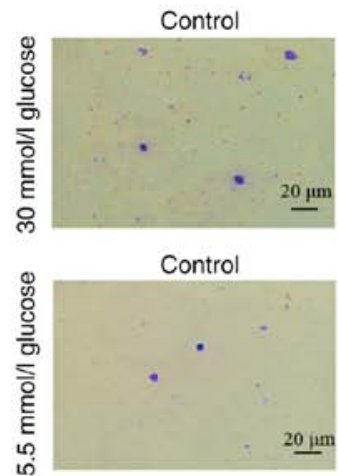

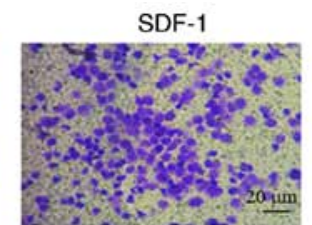

SDF-1

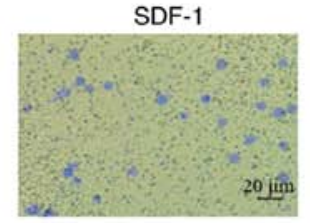

SDF-1

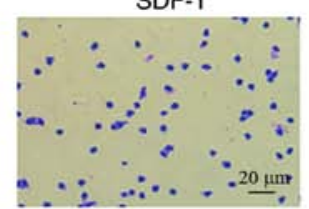

SDF-1

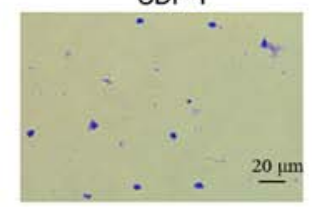

C

C 400

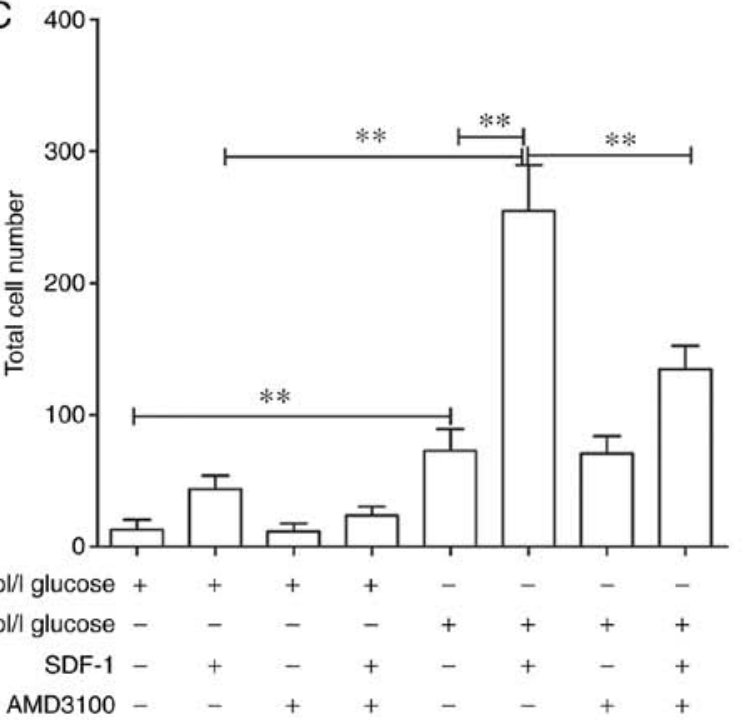

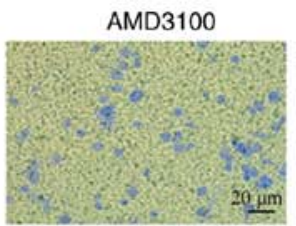

AMD3100

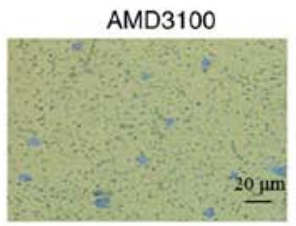

AMD3100

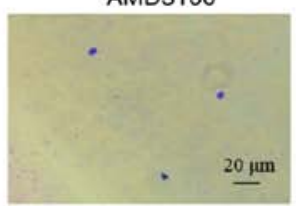

AMD3100
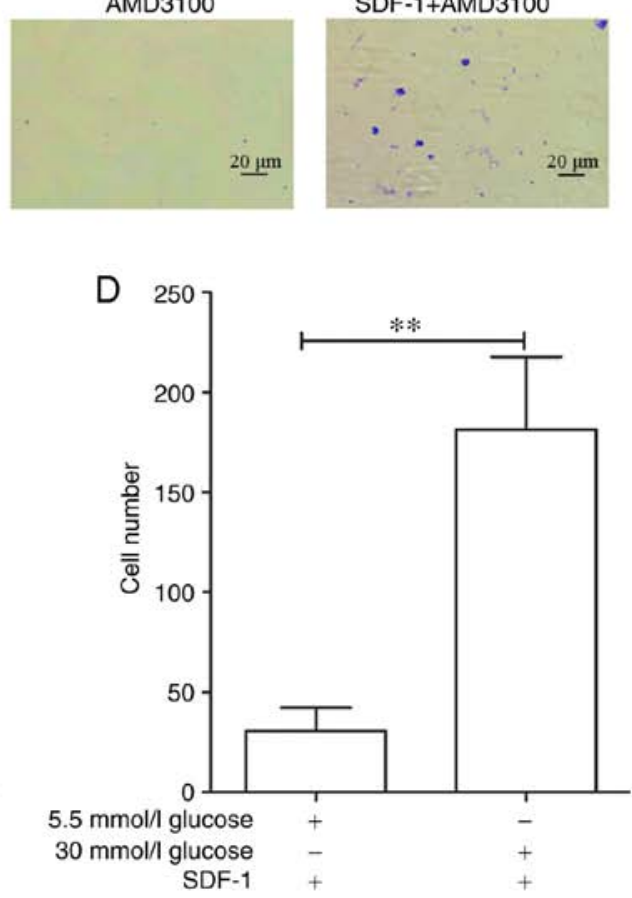

Figure 6. Effect of high glucose and AMD3100 on migration and invasion ability of circulating fibrocytes. (A) Number of cells in the bottom of the polycarbonate membrane after intervention with different glucose concentration DMEM. (B) Number of adherent cells through the polycarbonate membrane after intervention with different glucose concentration DMEM. (C) Statistical diagram of total cell number after intervention with different glucose concentration DMEM (total cell number=cells in the bottom of the polycarbonate membrane + adherent cells through the polycarbonate membrane); $30 \mathrm{mmol} / 1 \mathrm{glucose}$ vs. $5.5 \mathrm{mmol} / 1$ glucose, $30 \mathrm{mmol} / 1$ glucose vs. $30 \mathrm{mmol} / 1$ glucose+SDF-1, $30 \mathrm{mmol} / 1$ glucose+SDF-1 vs. $30 \mathrm{mmol} / 1 \mathrm{glucose}+\mathrm{SDF}-1+\mathrm{AMD} 3100,30 \mathrm{mmol} / 1$ glucose vs. $30 \mathrm{mmol} / 1$ glucose+AMD3100. (D) Number of transmembrane cells induced by SDF-1. ${ }^{* *} \mathrm{P}<0.01$. DMEM, Dulbecco's modified Eagle's medium; SDF-1, stromal cell-derived factor 1; ns, not significant.

the specific antagonist of CXCR4, could reduce a part of the changes caused by high glucose. These results suggested that circulating fibrocytes might be an important factor that leads to organs fibrosis in patients with diabetic cardiomyopathy via the CXCR4/SDF-1 axis. The present study may provide a different direction for understanding diabetes-caused fibrosis.

As described previously, the circulating fibrocytes derived from the bone marrow, differentiated from $\mathrm{CD} 14^{+}$monocytes and existed in the peripheral blood circulation, were considered as precursors of myofibroblasts (30). Previously, the double-positive expression of CD34 and COL-I or CD45 and COL-I was regarded as the accepted standard to identify circulating fibrocytes in the laboratory $(5,30)$. CD34 was selectively expressed on the surface of HSCs, reflecting that the fibrocytes are a type of bone marrow-derived cells. CD45 was the common surface antigen of leukocytes and the expression of both antigens (CD34 and CD45) were decreased during the differentiation process of circulating fibrocytes $(31,32)$. COL-I, the product of mesenchymal cells, is considered to be an important component of ECM and showed increased 


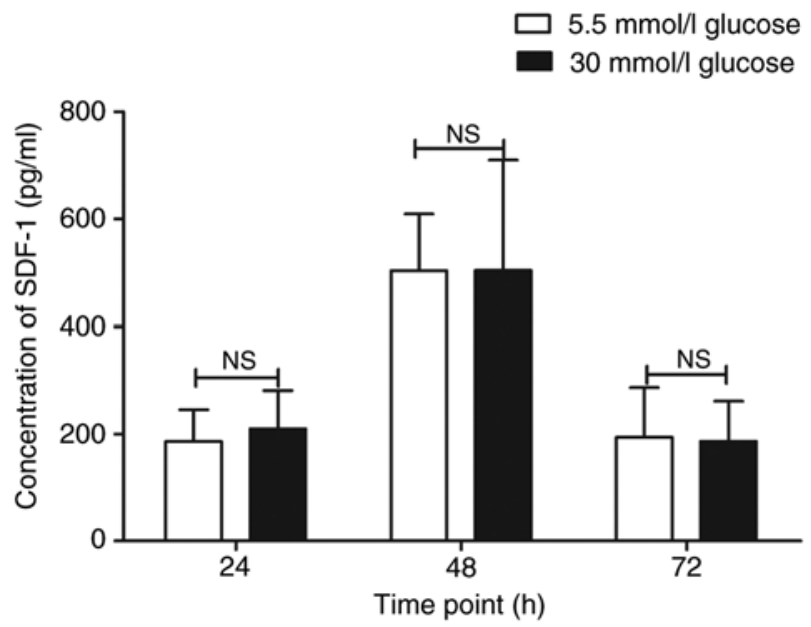

Figure 7. Effect of high glucose on the secretion of SDF-1 of circulating fibrocytes. The concentration of SDF-1 in three different time point. Pairwise comparisons between groups at different time points after intervention of two glucose concentration Dulbecco's modified Eagle's medium. Ns, not significant; SDF, stromal cell-derived factor 1 .

expression during cell differentiation. In the present study it was demonstrated that after 14 days of culture, the adherent cells expressed CD45 (green) and COL-I (red). After 21 days, the adherent cells only expressed COL-I, while the fluorescence of CD45 was hardly observed. In addition, as the culture time prolongs, the proportion of spindle-shape cells increasing in our pervious study. This was consistent with the results reported in the current literature (5). The results demonstrated that the obtained cells were indeed the circulating fibrocytes.

Beale et al (33) suggested that circulating fibrocytes served an important role in myocardial fibrosis by revealing that CD34, CD45 and collagen I expressed fibrocytes were increased in patients with ischemia-reperfusion induced myocardial fibrosis and post-MI scar formation. In addition, the secretion of collagen such as laminin was also significantly increased. Similarly, circulating fibrocytes were involved in the myocardial tissue of Mst-1 transgenic mice model of dilated cardiomyopathy and angiotensin II-induced cardiac hypertrophy model (34). Keeley et al (14) found that in patients with hypertensive heart disease, the total number of circulating fibrocytes in peripheral blood were significantly increased and showed a positive correlation with left ventricular mass index.

Further studies confirmed that diabetes can cause myocardial fibrosis and heart failure $(35,36)$. However, it is still not clear whether there was any relationship between diabetes, circulating fibrocytes and myocardial fibrosis. Previous flow cytometry experiments showed that the proportion of cells that co-express CD45 and COL-I in PBMCs of diabetic patients was increased compared with NGT patients $(1.93 \pm 1.01$ vs. $0.52 \pm 0.35 \%$ ) (12). Furthermore, in vitro experiments showed that high glucose DMEM stimulated the proliferation of circulating fibrocytes in a concentration-time dependent manner. When stimulated by $30 \mathrm{mmol} / 1$ glucose DMEM for $48 \mathrm{~h}$, the cell proliferation reached its peak (12). In addition, high glucose did not affect the apoptosis of circulating fibrocytes. Finally, high glucose increased the number of fibrocytes. These findings demonstrated that the increased circulating fibrocytes was probably the first step in organ fibrosis.
Current studies discovered that the effects of AMD3100 on cell proliferation are considered to be a double-edged sword. It could promote the proliferation of Ewing sarcoma cell lines in vitro (37), but also inhibited cancer cell growth and invasion $(38,39)$. AMD3100 showed no effect on cell proliferation in the present experiment. It was hypothesized that the CXCR4/SDF-1 axis may not have any effect on the proliferation and apoptosis of circulating fibrocytes. However more evidence is still warranted to confirm these results.

Several studies showed that circulating fibrocytes could secrete a variety of cytokines, including CCR3, CCR5, CCR7 (40-42). SDF-1, also known as chemokine 12(CXCL12), is a member of secreted CXC chemotactic protein superfamily and a specific ligand for CXCR4. The SDF-1/CXCR4 axis played an important role in lymphatic homing, tumor metastasis and embryonic development (43-45). CTGF, a member of the growth factor family, played an important role in cell proliferation, differentiation and migration, leading to fibrosis in multiple diseases, and hence is considered as one of the indicators of fibrosis. Previously, numerous studies have confirmed that SDF-1/CXCR4 axis promoted the expression of CTGF, eventually accelerating the process of fibrosis $(10,46)$. Lin et al (10) found that CTGF expression induced by CXCL12 showed a significant increase in patients with pulmonary fibrosis. Song et al (46) reported that AMD3100 could reduce bleomycin-induced lung fibrosis in mice, directly illustrating the role of CXCR4/SDF-1 axis in pulmonary fibrosis. The authors' previous western blotting results showed that the expressions of CXCR4 and CTGF in circulating fibrocytes were promoted by high glucose DMEM after $48 \mathrm{~h}$ intervention in a concentration dependent manner. To further explore whether the CXCR4/SDF-1 axis was the upstream signal of CTGF, AMD3100 was used to investigate the role of the CXCR4/SDF-1 axis in the expression of CTGF. As demonstrated, compared with the $30 \mathrm{mmol} / \mathrm{l}$ glucose DMEM group, the expression of CTGF was inhibited in the $30 \mathrm{mmol} / \mathrm{l}$ glucose+AMD3100 DMEM group. The results indicated that CTGF could be the downstream effector molecule of the CXCR4/SDF-1 axis. Furthermore, another important feature of fibrosis process was the deposition of ECM components, like COL-I, COL-III and so on (47). As shown by flow cytometry results, high glucose DMEM promoted the rate of cell expression of COL-I. Meanwhile, the application of AMD3100 inhibited the production of COL-I caused by high glucose. In conclusion, CXCR4/SDF-1 axis may be involved in the deposition of ECM proteins and played an indispensable role in the process of fibrosis.

Invasion and migration of cells to specific parts were prerequisites for numerous fibrotic pathophysiological processes (48-50). Whether high glucose could affect the invasion and migration abilities of fibrocytes was explored by Transwell assay. As expected, the total number of transmembrane cells was increased in the $30 \mathrm{mmol} / 1$ glucose group compared with the $5.5 \mathrm{mmol} / \mathrm{l}$ glucose group. These results may be associated with increased expression of matrix metalloproteinases (MMPs) and for the ability of circulating fibrocytes to secrete MMPs, including MMP2, MMP5 and MMP9. These results have been confirmed by several studies $(51,52)$; however, it still needed further experiments, like gelatin 
zymography, for verification. Compared with the $30 \mathrm{mmol} / \mathrm{l}$ glucose group, the total number of transmembrane cells was increased in the $30 \mathrm{mmol} / 1$ gluose+SDF-1 group. Similar results were obtained in the $5.5 \mathrm{mmol} / \mathrm{l}$ glucose DMEM group (data not shown). Furthermore, compared with $5.5 \mathrm{mmol} / \mathrm{l}$ glucose+SDF-1 group, the transfer ability of $30 \mathrm{mmol} / \mathrm{l}$ glucose+SDF-1 group was improved. Meanwhile, AMD3100 treatment partially decreased the number of trans-membrane cells. Combined with the results from western blotting as described in the authors' previous experiments (12), high glucose may affect cell migration by regulating the expression of CXCR4. These results indicated that CXCR4/SDF-1 axis may play an important role in the migration of fibrocytes.

Interestingly, there were no significant differences in SDF-1 secretion between $30 \mathrm{mmol} / \mathrm{l}$ glucose group and $30 \mathrm{mmol} / \mathrm{l}$ glucose $+100 \mu \mathrm{mmol} / \mathrm{l}$ AMD3100 group. In addition, AMD3100 did not completely inhibit the migration promoted by SDF-1. This might be due to the fact that the CXCR4/SDF-1 axis is not the only way to induce the transfer of fibrocytes. Numerous studies have suggested that other signaling pathways, such as the CX3CL1/CX3CR1 axis and CCL2/CCR2, may also participate in the migration of fibrocytes $(41,53)$. Blocking the CXCR4/SDF-1 axis may not be able to prevent the migration of circulating fibrocytes completely.

Studies have reported that SDF-1 is significantly elevated in the serum of patients with diabetes $(54,55)$. Circulating fibrocytes showed autocrine signaling of SDF-1, which in turn may also affect the results of migration experiments. However, there was no significant difference between $5.5 \mathrm{mmol} / \mathrm{l}$ glucose and $30 \mathrm{mmol} / 1$ glucose groups and demonstrated that high glucose may not have an effect on the secretion of SDF-1. Interestingly, the secretion of SDF-1 reached peak at $48 \mathrm{~h}$, which was similar to the result of CCK-8 assay in our pervious experiment (12). The authors of the present study suspected that the nutrient content of the culture fluid and the density of the inoculated cells together may affect the results of the experiment, but further investigations were required.

The effects of high glucose on the pathophysiological role of circulating fibrocytes in vitro were explored. Nevertheless, the present study had some limitations. Firstly, although the cells cultured for 14 days were identified by immunofluorescence, the purity of the obtained cells was not verified further. The purity of cells may have certain effects on the results of the experiment. Secondly, the present study on the mechanism of the CXCR4/SDF-1 was not in-depth. Although a series of appearances of cell changes caused by high glucose and applied AMD3100, the specific inhibitor of CXCR4, which proved that CXCR4/SDF-1 did play a role in certain pathophysiology process from the other aspect was elaborated on, what signal path the CXCR4/SDF-1 axis regulates these functions through was not further clarified. In addition a certain amount of literature about the CXCR4/SDF-1 axis was consulted. Lin et al (10) found that CXCL12 could induced the expression of CTGF of human lung fibroblasts according the Rac1/ERK, JNK and AP-1 pathways. Kajiyama et al (56) found that expression of dipeptidyl peptidase IV (DPPIV) and CXCR4 increased on human peritoneal mesothelial cells (HPMCs) by transforming growth factor (TGF)- $\beta 1$ treatment, TGF- $\beta 1$, DPPIV and the CXCR4/SDF-1 axis played crucial roles in regulating the migratory potential of HPMCs. In brief, the CXC4/SDF-1 axis participated in numerous pathophysiological processes. These existing studies provided a good starting point. Due to a number of different reasons, like funds and time, the present study had to stop here. The authors hope to do more in-depth research in this area in the future.

In conclusion, the present study demonstrated that high glucose DMEM stimulated the proliferation, invasion and migration of circulating fibrocytes, promoted the expression of ECM proteins including COL-I and CTGF. Application of specific blockers of CXCR4/SDF-1 axis may help in reducing the ability of fibrosis and providing a therapeutic strategy for the treatment of diabetic fibrosis in the future.

\section{Acknowledgements}

Not applicable.

\section{Funding}

The present study was supported by grants obtained from the Scientific Technological Projects for Medicine and Health of Zhejiang Province (grant no. 2015128660), the Natural Science Foundation of Zhejiang province (Project for Young Scientists; grant no. LQ13H020004), the National Natural Science Foundation of China (grant no. 81500284) and the Major Research and Development Project for the Zhejiang Science and Technology Agency (grant no. 2017C03034).

\section{Availability of data and materials}

All data generated or analyzed during this study are included in this published article.

\section{Authors' contributions}

YW and JL performed the experiments and wrote the manuscript. XL and SL obtained venous blood samples. CX performed statistical analysis. CD and LT were led the experiments of the current study and provided technological assistance.

\section{Ethics approval and consent to participate}

Ethics approval was obtained from the Ethics Committee of Zhejiang Hospital prior to the start of the study. All human procedures were performed in accordance with the declaration of Helsinki. All patients signed informed consent.

\section{Patient consent for publication}

The patient, parent, guardian or next of kin (in case of deceased patients) provided written informed consent for the publication of any associated data and accompanying images.

\section{Competing interests}

The authors declare that they have no competing interests. 


\section{References}

1. Hayat SA, Patel B, Khattar RS and Malik RA: Diabetic cardiomyopathy: Mechanisms, diagnosis and treatment. Clin Sci (Lond) 107: 539-557, 2004.

2. Fang ZY, Prins JB and Marwick TH: Diabetic cardiomyopathy: Evidence, mechanisms, and therapeutic implications. Endocr Rev 25: 543-567, 2015.

3. Zhang L, Zhou LN, Shen ZZ, Zhang XY, Yin M, Liu GZ, Guo P and ZhuXX: Effects of myocardial fibroblasts on fibrosis in diabetic cardiomyopathy. Fudan Univ J Med Sci 29: 399-402, 2002 (In Chinese)

4. Bucala R, Spiegel LA, Chesney J, Hogan M and Cerami A: Circulating fibrocytes define a new leukocyte subpopulation that mediates tissue repair. Mol Med 1: 71-81, 1994.

5. Varcoe RL, Mikhail M, Guiffre AK, Pennings G, Vicaretti M, Hawthorne WJ, Fletcher JP and Medbury HJ: The role of the fibrocyte in intimal hyperplasia. J Thromb Haemost 4: 1125-1133, 2010.

6. Gomer R and Pilling D: Compositions and methods for suppressing fibrocytes and for detecting fibrocyte differentiation. Analyst 2: 217-220, 2010.

7. Laws DA, Kraft AS, Leddy LR and Larue AC: Abstract A46: The role of circulating fibroblast precursors in promoting metastatic sarcoma. Cancer Res 75 (Suppl 1): A46, 2015.

8. Li C, Li X, Deng C and Guo C: Circulating fibrocytes are increased in neonates with bronchopulmonary dysplasia. PLoS One 11: e0157181, 2016.

9. Trimble A, Gochuico BR, Markello TC, Fischer R, Gahl WA, Lee JK, Kim Y, Burdick MD, Strieter RM and Mehrad B: Circulating fibrocytes as biomarker of prognosis in Hermansky-Pudlak syndrome. Am J Respir Crit Care Med 190: 1395-1401, 2014

10. Lin $\mathrm{CH}$, Shih $\mathrm{CH}$, Tseng $\mathrm{CC}$, Yu CC, Tsai YJ, Bien MY and Chen BC: CXCL12 induces connective tissue growth factor expression in human lung fibroblasts through the Rac1/ERK, JNK, and AP-1 pathways. PLoS One 9: e104746, 2014.

11. Behjati $\mathrm{M}$ and Hashemi M: Application of fibrocytes in the treatment of diabetic foot: As a potential new therapeutic approach. Diabetes Res Clin Pract 86: 152-153, 2009.

12. Weng Y, Qi J, Du C, Liu X, Xu C, Zeng G and Tang L: Effect of high glucose on circulating fibrocytes proliferation and the expression of CXCR4 and CTGF. Chin J Diabetes 26: 227-233, 2018 (In Chinese).

13. Murray LA: Commonalities between the pro-fibrotic mechanisms in COPD and IPF. Pulm Pharmacol Ther 25: 276-280, 2012.

14. Keeley EC, Mehrad B, Janardhanan R, Salerno M, Hunter JR, Burdick MM, Field JJ, Strieter RM and Kramer CM: Elevated circulating fibrocyte levels in patients with hypertensive heart disease. J Hypertens 30: 1856-1861, 2012.

15. White MJV, Galvis-Carvajal E and Gomer RH: A brief exposure to tryptase or thrombin potentiates fibrocyte differentiation in the presence of serum or SAP. J Immunol 194: 142-150, 2015.

16. Ulmer AJ, Scholz W, Ernst M, Brandt E and Flad HD: Isolation and subfractionation of human peripheral blood mononuclear cells (PBMC) by density gradient centrifugation on percoll. Immunobiology 166: 238-250, 1984.

17. Quan TE, Cowper S, Wu SP, Bockenstedt LK and Bucala R: Circulating fibrocytes: Collagen-secreting cells of the peripheral blood. Int J Biochem Cell Biol 36: 598-606, 2004.

18. Schmidt M, Sun G, Stacey MA, Mori L and Mattoli S Identification of circulating fibrocytes as precursors of bronchial myofibroblasts in asthma. J Immunol 171: 380-389, 2003.

19. Wu Y, Zhou J, Wang H, Wu Y, Gao Q, Wang L, Zhao Q, Liu P, Gao S, Wen W, et al: The activation of p38 MAPK limits the abnormal proliferation of vascular smooth muscle cells induced by high sodium concentrations. Int J Mol Med 37: 74-82, 2016.

20. Zhou YK and Xue YM: High glucose inhibiting proliferation of RSC96 schwann cells by high osmotic pressure. J Kunming Univ Sci Technol 38: 60-64, 2013 (In Chinese).

21. Chen HT, Wang DY, Geng HZ, Chen HQ, Wu YX, Deng SQ and Wang ZL: Adiponectin exerts antiproliferative effect on high glucose-induced BeWo cell proliferation in vitro. Zhonghua Fu Chan Ke Za Zhi 51: 204-208, 2016 (In Chinese).

22. Ho FM, Liu SH, Lin WW and Liau CS: Opposite effects of high glucose on MMP-2 and TIMP-2 in human endothelial cells. J Cell Biochem 101: 442-450, 2010.

23. Marchesi F, Monti P, Leone BE, Zerbi A, Vecchi A, Piemonti L, Mantovani A and Allavena P: Increased survival, proliferation, and migration in metastatic human pancreatic tumor cells expressing functional CXCR4. Cancer Res 64: 8420-8427, 2004.
24. Rodríguez-Nieves JA, Patalano SC, Almanza D, GharaeeKermani $M$ and Macoska JA: CXCL12/CXCR4 axis activation mediates prostate myofibroblast phenoconversion through non-canonical EGFR/MEK/ERK signaling. PLoS One 11: e0159490, 2016.

25. Pandey DP, Lappano R, Albanito L, Madeo A, Maggiolini M and Picard D: Estrogenic GPR30 signalling induces proliferation and migration of breast cancer cells through CTGF. EMBO J 28 523-532, 2014.

26. Li M, Xie Z, Wang P, Li J, Liu W, Tang S, Liu Z, Wu X, Wu Y and Shen $\mathrm{H}$ : The long noncoding RNA GAS5 negatively regulates the adipogenic differentiation of MSCs by modulating the miR-18a/CTGF axis as a ceRNA. Cell Death Dis 9: 554, 2018.

27. Wang J, Duan L, Guo T, Gao Y, Tian L, Liu J, Wang S and Yang J: Downregulation of miR-30c promotes renal fibrosis by target CTGF in diabetic nephropathy. J Diabetes Complications 30: 406-414, 2016.

28. Wu Y, Wang W, Peng XM, He Y, Xiong YX, Liang HF, Chu L, Zhang BX, Ding ZY and Chen XP: Rapamycin upregulates connective tissue growth factor expression in hepatic progenitor cells through TGF- $\beta$-Smad 2 dependent signaling. Front Pharmacol 9: 877, 2018.

29. Guan S and Zhou J: Frizzled-7 mediates TGF- $\beta$-induced pulmonary fibrosis by transmitting non-canonical Wnt signaling. Exp Cell Res 359: 226-234, 2017.

30. Chiang HY, Chu PH and Lee TH: R1R2 peptide ameliorates pulmonary fibrosis in mice through fibrocyte migration and differentiation. PLoS One 12: e0185811, 2017.

31. Lassance L, Marino GK, Medeiros CS, Thangavadivel S and Wilson SE: Fibrocyte migration, differentiation and apoptosis during the corneal wound healing response to injury. Exp Eye Res 170: 177-187, 2018.

32. Nakamichi M, Akishimafukasawa Y, Fujisawa C, Mikami T, Onishi $\mathrm{K}$ and Akasaka Y: Basic fibroblast growth factor induces angiogenic properties of fibrocytes to stimulate vascular formation during wound healing. Am J Pathol 186: 3203-3216, 2016.

33. Beale A, Fang L, Ellims A, Ling L, Taylor A, Chin-Dusting J and Dart A: Fibrocytes, a novel fibroblast-like population, are increased in cardiac fibrosis. Heart Lung Circ 21: (Suppl 1): S59-S59, 2012.

34. Haudek SB, Cheng J, Du J, Wang Y, Hermosillo-Rodriguez J, Trial J, Taffet GE and Entman ML: Monocytic fibroblast precursors mediate fibrosis in angiotensin-II-induced cardiac hypertrophy. J Mol Cell Cardiol 49: 3499-507, 2010.

35. Russo I and Frangogiannis NG: Diabetes-associated cardiac fibrosis: Cellular effectors, molecular mechanisms and therapeutic opportunities. J Mol Cell Cardiol 90: 84-93, 2016.

36. Feng B, Chen S, Gordon AD and Chakrabarti S: miR-146a mediates inflammatory changes and fibrosis in the heart in diabetes. J Mol Cell Cardiol 105: 70-76, 2017.

37. Berning P, Schaefer C, Clemens D, Korsching E, Dirksen U and Potratz J: The CXCR4 antagonist plerixafor (AMD3100) promotes proliferation of Ewing sarcoma cell lines in vitro and activates receptor tyrosine kinase signaling. Cell Commun Signal 16: 1-13, 2018.

38. Reeves PM, Abbaslou MA, Kools FRW and Poznansky MC: CXCR4 blockade with AMD3100 enhances Taxol chemotherapy to limit ovarian cancer cell growth. Anticancer Drugs 28: 935-942, 2017.

39. Li JK, Yu L, Shen Y, Zhou LS, Wang YC and Zhang JH: Inhibition of CXCR4 activity with AMD3100 decreases invasion of human colorectal cancer cells in vitro. World J Gastroenterol 14: 2308-2313, 2008

40. Ishida Y, Kimura A, Nosaka M, Kuninaka Y, Hemmi H, Sasaki I, Kaisho T, Mukaida N and Kondo T: Essential involvement of the CX3CL1-CX3CR1 axis in bleomycin-induced pulmonary fibrosis via regulation of fibrocyte and M2 macrophage migration. Sci Rep 7: 16833, 2017.

41. Phillips RJ, Burdick MD, Hong K, Lutz MA, Murray LA, Xue YY, Belperio JA, Keane MP and Strieter RM: Circulating fibrocytes traffic to the lungs in response to CXCL12 and mediate fibrosis. J Clin Invest 114: 438-446, 2004.

42. Ishida Y, Kimura A, Kondo T, Hayashi T, Ueno M, Takakura N, Matsushima K and Mukaida N: Essential roles of the CC chemokine ligand 3-CC chemokine receptor 5 axis in bleomycininduced pulmonary fibrosis through regulation of macrophage and fibrocyte infiltration. Am J Pathol 170: 843-854, 2007.

43. Luo X, Wang X, Xia Z, Chung SK and Cheung CW: CXCL12/CXCR4 axis: An emerging neuromodulator in pathological pain. Rev Neurosci 27: 83-92, 2016. 
44. Katsura M, Shoji F, Okamoto T, Shimamatsu S, Hirai F, Toyokawa G, Morodomi Y, Tagawa T, Oda Y and Maehara Y: Correlation between CXCR4/CXCR7/CXCL12 chemokine axis expression and prognosis in lymph-node-positive lung cancer patients. Cancer Sci 109: 154-165, 2018.

45. Ho SY, Ling TY, Lin HY, Liou JT, Liu FC, Chen IC, Lee SW, Hsu Y, Lai DM and Liou HH: SDF-1/CXCR4 signaling maintains stemness signature in mouse neural stem/progenitor cells. Stem Cells Int 2017: 2493752, 2017.

46. Song JS, Kang CM, Kang HH, Yoon HK, Kim YK, Kim KH, Moon HS and Park SH: Inhibitory effect of CXC chemokine receptor 4 antagonist AMD3100 on bleomycin induced murine pulmonary fibrosis. Exp Mol Med 42: 465-476, 2010.

47. Chun TH: Peri-adipocyte ECM remodeling in obesity and adipose tissue fibrosis. Adipocyte 1: 89-95, 2012.

48. Friedl P and Gilmour D: Collective cell migration in morphogenesis, regeneration and cancer. Nat Rev Mol Cell Biol 10: 445-457, 2009.

49. Wolf K, Mazo I, Leung H, Engelke K, von Andrian UH, Deryugina EI, Strongin AY, Bröcker EB and Friedl P: Compensation mechanism in tumor cell migration: Mesenchymal amoeboid transition after blocking of pericellular proteolysis. J Cell Biol 160: 267-277, 2003.

50. Sandbothe M, Buurman R, Reich N, Greiwe L, Vajen B, Gürlevik E, Schäffer V, Eilers M, Kühnel F, Vaquero A, et al: The microRNA-449 family inhibits TGF- $\beta$-mediated liver cancer cell migration by targeting SOX4. J Hepatol 66: 1012-1021, 2017.

51. Galligan CL and Fish EN: Circulating fibrocytes contribute to the pathogenesis of collagen antibody-induced arthritis. Arthritis Rheum 64: 3583-3593, 2012.
52. Craig VJ, Zhang L, Hagood JS and Owen CA: Matrix metalloproteinases as therapeutic targets for idiopathic pulmonary fibrosis. Am J Respir Cell Mol Biol 53: 585-600, 2015.

53. Singh SR, Sutcliffe A, Kaur D, Gupta S, Desai D, Saunders R and Brightling CE: CCL2 release by airway smooth muscle is increased in asthma and promotes fibrocyte migration. Allergy 69: 1189-1197, 2014.

54. Derakhshan R, Arababadi MK, Ahmadi Z, Karimabad MN, Salehabadi VA, Abedinzadeh M, Khorramdelazad H, Balaei P, Kennedy D and Hassanshahi G: Increased circulating levels of SDF-1 (CXCL12) in type 2 diabetic patients are correlated to disease state but are unrelated to polymorphism of the SDF-1 $\beta$ gene in the Iranian population. Inflammation 35: 900-904, 2012.

55. Lovshin JA, Rajasekeran H, Lytvyn Y, Lovblom LE, Khan S, Alemu R, Locke A, Lai V, He H, Hittle L, et al: Dipeptidyl peptidase-4 inhibition stimulates distal Tubular natriuresis and increases in circulating SDF-1 $\alpha$ (1-67) in patients with type 2 diabetes. Diabetes Care 40: 1073-1081, 2017.

56. Kajiyama H, Shibata K, Ino K, Nawa A, Mizutani S and Kikkawa F: Possible involvement of SDF-1alpha/CXCR4-DPPIV axis in TGF-betal-induced enhancement of migratory potential in human peritoneal mesothelial cells. Cell Tissue Res 330: 221-229, 2007.

This work is licensed under a Creative Commons Attribution-NonCommercial-NoDerivatives 4.0 International (CC BY-NC-ND 4.0) License. 